\title{
Una mirada a las sociedades unipersonales en pos de su admisibilidad en el ordenamiento jurídico nacional ${ }^{22}$
}

\author{
Fabiola Urbina Sotomayor \\ Labora en el Ministerio de Transporte e Infraestructura \\ fabiolaurbina@hotmail.com
}

\section{Resumen}

Cuando se estudian las sociedades capitalistas, una de las figuras que destaca por su importancia práctica y por su riqueza dogmática- es la figura de la sociedad unipersonal. En la realidad jurídica de Nicaragua, la sola mención de la figura aún es un término ajeno, a pesar de que Nicaragua, en su Código de Comercio (art.270) reconoce la unipersonalidad sobrevenida, de forma claudicante o meramente transitoria, impidiendo la originaria a la manera que hicieron los códigos de su tiempo y anteriores a él. En razón lo antes expuesto es que me he planteado abordar el estudio de este tema a fin de valorar la posible inclusión, amplia, plena, de las sociedades unipersonales -originarias y sobrevenidas- en nuestra legislación.

Palabras clave: sociedad/ unipersonal/ admisibilidad

\begin{abstract}
When studying capitalist companies, one of the figures that highlights - for its practical importance and dogmatic richness- is the figure of the one-person company. In the Nicaragua's legal reality, the mere mention of this figure is still a foreign term, despite the fact that Nicaragua, in its Commercial Code (art. 270) recognizes the supervened sole person company, in a merely transient way, preventing the original, the way that the codes of his time were made and before it. Because the foregoing is that, I have considered approaching the study of this topic, in order to evaluate the possible inclusion, in a wide and extensive way of the sole person companies, --originals or supervened,-- in our legislation.
\end{abstract}

Key words: society/ unipersonal/ admissibility

22 El presente artículo es el resultado del trabajo de investigación del I ciclo académico de la Maestría en Derecho de las Contrataciones; el cual además de ser evaluado por un Tribunal integrado por tres académicos; posteriormente, fue arbitrado por una Comisión a efectos de seleccionar a los participantes del II Encuentro de Investigación de Postgrado de la Universidad Centroamericana, Agosto 2010. 


\section{Introducción}

Cuando se estudian las sociedades capitalistas, una de las figuras que destaca - por su importancia práctica, por su riqueza dogmática- es la figura de la sociedad unipersonal. Esta figura goza de una gran riqueza doctrinal para estudiosos del Derecho Mercantil y ha encontrado cobija normativa en un sinnúmero de legislaciones, tal es el caso del contexto español y colombiano, por sólo citar algunos.

En la realidad jurídica de Nicaragua, la sola mención de la figura aún es un término ajeno, que con relativo retraso se ha comenzado a introducir en los espacios de debate académico, a pesar de que Nicaragua, en su Código de Comercio (art.270) reconoce la unipersonalidad sobrevenida, de forma claudicante o meramente transitoria -pero reconocida al fin- impidiendo la originaria a la manera que hicieron los códigos de su tiempo y anteriores a él. El tratamiento doctrinal extenso que ha venido ganado esta figura, el reconocimiento normativo moderno que ha logrado en países con ordenamientos jurídicos de avanzada, el reconocimiento controvertido que hace nuestro Código, de ella y la realidad de las relaciones de mercado en Nicaragua, que aconsejan su admisión expresa $a b$ initio, han fundado mi interés en la investigación de este tema, sobre lo cual adelanto que nuestra legislación se encuentra desfasada con relación a otros países no sólo del área, sino además del contexto europeo que si la tienen normadas, a pesar de que nuestra realidad de hoy es idéntica a la que en su día tuvieron aquellos contextos que reconocen con esplendor la mencionada figura.

En razón de todo lo antes expuesto es que me he planteado abordar el actual estudio a los fines de valorar la inclusión, amplia, plena, de las sociedades unipersonales -originarias y sobrevenidas- en nuestra legislación, ya que a la fecha únicamente la sociedad unipersonal sobrevenida, como ha quedado dicho, se encuentran regulada y dicho sea con extrema palidez y controversia legal, según nuestra vigente ley mercantil.

También es importante el estudio de estetema, porque en nuestra realidad es ampliamente conocido que los empresarios utilizan a testaferros o bien "hombres de paja" (término empelado en la exposición de motivos del Texto Refundido de la Ley de Sociedades Anónimas española, Real 
Decreto Legislativo 1564/1989 de 22 de diciembre, publicado en el Boletín Oficial del Estado español de 27 de diciembre de 1989) que en esencia crean meras apariencias legales de pluralidad, con el fin de cumplir con los requerimientos para constituir una sociedad, siendo evidente la carencia del ánimo de permanencia en la sociedad, pues simplemente los hombres de paja son utilizados para terminar evadiendo la norma al pasar sus acciones o particiones sociales a manos del socio que tenía verdaderamente el ánimo de constituir la sociedad; convirtiéndose, de esta manera, en una sociedad unipersonal sobrevenida, sino formal al menos de facto, lo que se evitaría y al mismo tiempo se regularía si la norma nicaragüense permitiera constituir sociedades con un solo socio.

De esta manera los empresarios individuales contarían con un mecanismo legal para proteger su patrimonio personal del patrimonio utilizado en sus operaciones mercantiles, puesto que al constituir la sociedad unipersonal y al dotar a esta de un patrimonio propio, se hace una clara diferenciación entre el patrimonio social y el personal.

Adoptar una posición legal propositiva y sustentada sobre este tema, que de alguna forma sirva de orientación a los operadores jurídicos empresariales, que es justo mi mayor propósito con este trabajo, exige presentar un estudio aunque sea somero, sobre los puntos medulares de esta figura ello supone transitar primero por un recorrido histórico que nos ilustre como se ha comportado a lo largo de la historia su tratamiento doctrinal y positivo. Luego, esbozar su fundamento dogmático y por último nutrirnos de lo anterior, traspolar esas ideas al análisis del Derecho interno, con el fin de determinar cómo estamos respecto de él y hacia dónde debemos tender.

\section{Breve recorrido histórico de las sociedades unipersonales}

\section{Necesaria referencia al surgimiento de la sociedad en general}

Para comenzar a abordar el tema de las sociedades unipersonales, se hace necesario realizar una breve reseña histórica de los primeros vestigios de las sociedades mercantiles y cómo luego, de éstas, emergen las sociedades capitalistas y a su vez cómo de las sociedades anónimas y las sociedades de responsabilidad limitada se deriva la posibilidad de poder constituirlas; bien, con una pluralidad de socios o bien, con un socio unipersonal; admitiéndose de este modo las sociedades unipersonales. 
Según el autor Joaquín Rodríguez Rodríguez (1977), la evolución histórica de las empresas mercantiles debe ser estudiada a partir de la historia dinámica de las relaciones comerciales que ha marcado cada época.

Así las cosas, las sociedades mercantiles inicialmente fueron de carácter momentáneo, ya que las mismas eran creadas para realizar un objetivo determinado, el cual era realizado en un espacio de tiempo breve. En el caso de las sociedades de carácter ocasional, éstas inician en Europa, con la llamada commenda, contrato que consistía en "el encargo dado por el commendator al tractor para que éste opere con el dinero o las mercancías que aquél le proporciona” (Rodríguez, 1977, p. 2).

Posteriormente a la commenda, surgen sociedades de tipo permanente, las que han perdurado en el tiempo, hasta la actualidad. Estas sociedades se manifiestan en dos tipos, la sociedad colectiva y la sociedad comandita, última ésta que deriva de la commenda.

En el caso de la sociedad colectiva, esta nace cerca de siglo XIII, con rasgos muy similares a la sociedad colectiva que conocemos hoy en día, puesto que nace como una sociedad netamente familiar, ya que su esencia es la confianza que existe entre sus socios, de lo cual deriva su sistema de responsabilidad patrimonial personal e ilimitado, razones éstas, entre otras, por la que dicha sociedad es de carácter personalista. En estos casos, la actividad comercial o artesanal individual se transformó en una sociedad conformada por los hijos o herederos de comerciantes o artesanos.

En el transcurso de la evolución histórica que venimos narrando constituye un peldaño superior el nacimiento de las sociedades capitalistas, las que surgen - tal y como lo narran la inmensa mayoría de los textos en la materia- entre el siglo XVII y XIX, tiempo en que las mismas evolucionan y se perfeccionan. Este período fue de vital importancia en la madurez y plenitud de las sociedades mercantiles, puesto que en dicha época ocurre la Revolución Industrial, época que resultó perfecta para que las sociedades capitalistas fueran desarrolladas, dada la bondad que mostraron en la separación de responsabilidad, la flexibilidad en la transmisión de las participaciones sociales y la relevancia que tomó el patrimonio social, todo lo cual permitió ofrecer mejor molde a las exigencias del dinamismo comercial, que impuso la Revolución Industrial. 
Uría, Menéndez \& García de Enterría (1999) aportan un recorrido detenido sobre el surgimiento del origen y evolución de las sociedades anónimas, que es menester consultar y que en este espacio, por su naturaleza, sintetizo.

Según los autores, por el año XVII se da el nacimiento de las sociedades anónimas, el cual está ligado a la creación de las compañías que atendían el comercio que se estaba desarrollando con las Indias Orientales y Occidentales, en virtud del descubrimiento de las nuevas rutas de comercio con las Indias, pues por el peligro y riesgos que representaba el enfrentar estas expediciones, se dio el momento oportuno para el nacimiento de las sociedades anónimas; pues, tales peligros y riesgos no podían ser asumidos por sociedades de índole personalista, dado que este tipo de sociedad además de sus socios estar vinculados por lazos de familiaridad y de pocos socios que respondían ilimitadamente, se excedía el riesgo que una sociedad de este tipo podía asumir, al estar en juego la totalidad del patrimonio de sus socios.

En virtud de lo anterior, es que se gesta el clima propicio para el nacimiento de las sociedades anónimas, que fueron creadas con la idea de dividir el capital en pequeñas partes. Estas partes fueron denominadas acciones las que tuvieron como propósito crear un mecanismo que facilitara la reunión de capital que se requería para poder llevar a cabo la empresa, el tráfico comercial con las Indias y de esta forma el riesgo estaba repartido en muchas manos que respondían hasta el monto por éstos aportados.

El primer ejemplo palpable de una sociedad anónimas es la Compañía holandesa de las Indias Orientales, que nació en el año 1602, después otras compañías siguieron su ejemplo; sin embargo estas compañías a pesar de tener dividido su capital en acciones, son muy distintas a las sociedades anónimas que hoy en día conocemos pues en un inicio "eran entidades semipúblicas, constituidas directamente por los soberanos mediante decisiones gubernativas que les dotaban de personalidad y les conferían privilegios monopolísticos en la explotación comercial" (Uría, Menéndez, \& otros, 1999, p. 166).

Es con la Revolución Francesa que la sociedad anónima evoluciona a la forma societaria que hoy en día conocemos y a través del Código de Comercio Napoleónico, puesto que la misma es separada del Estado 
y su fundación pasa ser por voluntad de los socios, aunque estuviera supeditada a la previa concesión o autorización del Estado, con el fin de controlar la legalidad y la eficacia de su constitución.

El Código Español de 1829, se limita a exigir la aprobación de las escrituras fundacionales por los Tribunales de Comercio, así mismo se retira la injerencia del Estado en la vida de la sociedad y se deja establecido que ésta únicamente va a estar dirigida por la voluntad de los socios, en democracia e igualdad de derechos.

En el siglo XIX, la constitución de las sociedades anónimas está exclusivamente vinculada a la voluntad de los socios quienes por su propia voluntad deciden constituir una sociedad, sin que el Estado deba autorizar la pretensión de los socios; sin embargo siempre se deben tener presente los requisitos legales que son de ineludible cumplimiento para la constitución organización y funcionamiento de la sociedad, además del control que realiza el Registro Público Mercantil en cuanto a la legalidad del pacto social y la publicidad del mismo para terceros.

La tendencia a utilizar las formas de sociedad mercantil, de responsabilidad limitada y la anónima, como estructuras de limitación de la responsabilidad y no como formas de organización colectiva, fue cada vez más notoria, desde entonces, y así llega a nuestros días. El empresario, antes comerciante, ve en las sociedades capitalistas el instrumento legal idóneo para salvaguardar su patrimonio personal de la ventura de su actividad empresarial.

De lo anteriormente expuesto, podemos concluir que la sociedad mercantil a lo largo de la historia ha evolucionado, y de esta evolución se hizo presente la necesidad de normar los diversos tipos de sociedades mercantiles; siendo el Código Civil Francés o Código Napoleónico -vigente a pesar de haber sufrido importantes y numerosas reformas- el primer texto jurídico que se encarga de normar dicha figura, siendo que éste ha servido de base para las demás normas jurídicas promulgadas por otras naciones en cuanto a la regulación de las sociedades mercantiles.

\section{Historia de la unipersonalidad}

No es posible abordar la historia de las sociedades unipersonales sin antes ofrecer un esbozo de cómo evolucionaron las sociedades en general, pues en auténtica verdad las sociedades unipersonales no constituyen un tipo societario nuevo, sino una forma de estar de las sociedades capitalistas y esta visión más moderna, sólo es posible entenderla a partir de que 
se conozca la historia de los distintos tipos societarios, por ello se hizo menester presentar el acápite anterior para ahora detenernos en la historia de la unipersonalidad, que no es más que el cambio de visión doctrinal y positiva hacia las sociedades capitalistas.

Carbajo Cascón ( 2002) expone de manera precisa el origen de la sociedad unipersonal, por lo que a continuación me permito realizar una síntesis de lo por él señalado en relación con este tema.

El precursor de la figura de las sociedades unipersonales en el siglo XIX, fue el Principado de Liechtenstein, ya que el 20 de enero de 1926 permitieron en su cuerpo legislativo conforme a la propuesta realizada por Pisko, la conformación de empresas individuales de responsabilidad limitada y se reconoce la unipersonalidad $a b$ initio, pero no es hasta mediados del siglo XX que se da su reconocimiento positivo en otros ordenamientos jurídicos.

Sin embargo, desde el siglo XIX la sociedad unipersonal ha sido una figura relevante en la práctica jurídica y económica germana, puesto que se practica la reunión de las acciones de una sociedad anónima en un solo socio, con el objetivo de lograr de manera indirecta que se limitara la responsabilidad de un empresario individual al ser socio único o unipersonal de una sociedad anónima o bien de responsabilidad limitada.

Tras el reconocimiento legislativo de las sociedades de capital que podían ser constituidas con un mínimo de dos socios a través de la GmbHg -Ley de Sociedades de Responsabilidad Limitada de 1892-, en la que además limitaban su responsabilidad hasta el monto aportado por cada socio, dicho de otra manera hasta el capital social, se presentaban socios en la fundación que no tenían la intensión o voluntad de pertenecer a la sociedad y con éstos aparecen socios fiduciarios o testaferros, los que únicamente eran utilizados para evadir la norma y poder constituir la sociedad. Estos posteriormente trasmitían sus acciones o particiones sociales a un tercero el cual podía no en el momento de la constitución de la sociedad participar como socio, creándose de esta manera una sociedad unipersonal sobrevenida que según Carbajo Cascón (2002):

Incluso en la intensión de mantener en la sociedad como socios de conveniencia en interés de una sola persona que puede o no aparecer como socio de la entidad («Hintermann»), dando lugar a las llamadas sociedades de favor o conveniencia, que son sociedades materialmente unipersonales" (p. 50). 
La GmbH-Gesetz antes relacionada, ejerció una gran preponderancia y la misma fue recogida en la Ley austriaca de 1906, legislaciones con las que se creó un gran volumen de doctrina de los estudios realizados a estas legislaciones las primeras décadas después de su promulgación.

Siguiendo con Carbajo Cascón (2002):

La sociedad decapital, surgió en su día como una creación específica al tráfico jurídico (compañía de comercio privilegiada) para fomentar la explotación de empresas en régimen de monopolio en los territorios colonizados; distinta pues de las sociedades de mercaderes tradicionales que aparecieron espontáneamente en el medievo.

Sin embargo, es hasta mediados del siglo XX, momento en el cual se maximiza la utilidad de las sociedades de capital como un ente que sirve para organizar una empresa, puesto que por su estructura inminentemente patrimonial, no es de importancia el número de socios que la conforman, por lo que han dado la pauta para admitir sociedades unipersonales como formas de organizar una empresa.

La sociedad anónima y la sociedad de responsabilidad limitada o sociedades capitalistas, han sido el vehículo idóneo para que los pequeños empresarios o comerciantes, pudieran limitar su responsabilidad a lo aportado a la sociedad, puesto que de esta manera se separa su patrimonio del patrimonio societario, el cual es el que responde ante terceros.

Inicialmente la unipersonalidad sobrevenida fue permitida tácitamente, debido a que se guardaba la esperanza que la sociedad unipersonal retomara su pluralidad de socios. Es por esto, que la posibilidad de poder constituir una sociedad con un solo socio, ha sido permitida de forma paulatina a través de la jurisprudencia, para posteriormente encontrar reconocimiento en el derecho positivo de las naciones del primer mundo.

De acuerdo con Carbajo Cascón (2002) una vez que fueron dadas las condiciones económicas y jurídicas deseables, buscaba demostrar la oportunidad práctica y la licitud dogmática de la unipersonalidad sobrevenida y también - «a fortiori»- la unipersonalidad originaria, partiendo de una profunda revisión de los caracteres estructurales y funcionales de la sociedad de capital en general. 
Como podemos observar, la evolución de la sociedad de capital, resultó ser la forma organizacional de empresas perfecta para dar solución al problema de la delimitación de responsabilidad, que enfrentaba el empresario o comerciante individual, por lo que actualmente muchas legislaciones permiten que una sociedad capitalista sea constituida con socio único o bien naciendo con pluralidad de socios para posteriormente las acciones o particiones sociales recaer en una sola mano. Dada la posibilidad de delimitación de la responsabilidad, es que hoy en día las sociedades unipersonales han ganado notoriedad en el que hacer jurídico y comercial del mundo capitalista globalizado.

Es por esto, que al ser este un tema plenamente desarrollado en la doctrina y por los estudiosos del derecho, la secuencia lógica es el "otorgar un reconocimiento legislativo pleno a la sociedad de capital con un solo socio, no solo sobrevenida, por la concentración de todas las acciones o participaciones de una sociedad anónima o limitada en una sola mano, sino también "ab origine", (Carbajo Cascón, 2002, p. 63), siendo de esta forma más que innecesario el recurrir a los llamados hombres de paja o testaferros, que traía como consecuencia que las acciones o particiones sociales recayeran en mano de un solo socio, conformándose de esta forma una sociedad unipersonal sobrevenida.

Ejemplo del reconocimiento jurídico a las sociedades capitalistas unipersonales, es el otorgado en el viejo continente, con la promulgación por parte de la Unión Europea de la Duodécima Directiva CEE en materia de sociedades, de 21 de junio de 1989, sobre sociedades de responsabilidad limitada de un solo socio.

Como se puede observar, la historia de las sociedades unipersonales, precede las diversas reformas legislativas realizadas, con el fin de dar respuesta a un sector de la población que requería que su patrimonio personal fuera separado del patrimonio utilizado para realizar actos de comercio, o bien para normar aspectos concretos ya existentes en la realidad mercantil y que era necesario regularlos jurídicamente o bien para adaptar la legislación existente a las nuevas exigencias de los empresarios o comerciantes.

La sociedad unipersonal es considerada como un medio jurídico que permite hacer una separación clara y precisa entre la empresa constituida dela persona del empresario y de esta manera se facilita la comprensión de 
que la empresa es un ente independiente con patrimonio y personalidad propia muy distinto y diferenciado del patrimonio del empresario que es el accionista. Esto es evidenciado en el momento de constituir la sociedad, pues el empresario al ceder parte de su patrimonio a la sociedad que se constituye y lo convierte por así decirlo en las acciones o particiones que se emiten ya sea en el caso de una sociedad anónima o una sociedad de responsabilidad limitada, acciones o particiones que pasan a formar parte de su patrimonio personal, por lo que de una u otra forma lo que realiza es una transformación patrimonial; pero que al momento de tener la sociedad que asumir deudas o pagos a los proveedores éstos nunca podrán ir más allá del capital social, por lo que el patrimonio personal del socio queda de esta forma protegido.

Como ya se dijo, la necesidad de normar las sociedades unipersonales, se hizo evidente, puesto que las legislaciones ya consentían de manera tácita las sociedades unipersonales sobrevenidas, con la concentración de todas las acciones o particiones sociales en un mismo socio, sin que esto fuera causal de disolución de la sociedad, a menos que un tercero lo solicitara. Así mismo, contribuyó al reconocimiento legislativo de las sociedades unipersonales el que los empresarios requirieran delimitar su responsabilidad, y ésta es una de las razones fundamentales del por qué esta forma de estar de las sociedades capitalistas encuentra acogida en un sinnúmero de ordenamientos jurídicos.

Así mismo, de esta forma se evita la utilización de testaferros, o los llamados por la doctrina "hombres de paja", socios que no tienen la intensión o voluntad de pertenecer a la sociedad, ya que son utilizados únicamente con el fin de cumplir con la obligación legal exigida de un número determinado de socios para poder formalizar la constitución de una sociedad, ya sea anónima, o de responsabilidad limitada para posteriormente pasar las acciones o participaciones sociales a un único socio, cuando en el ordenamiento jurídico no está tácitamente establecido que de pasar el capital social a manos de un solo socio se configura automáticamente la disolución de la sociedad.

En algunos ordenamientos jurídicos en los que no está regulada la sociedad unipersonal originaria- caso del contexto nicaragüense- pero que sí admiten la unipersonalidad sobrevenida, al permitir que las acciones se reúnan en un solo socio, la propia Ley concede un plazo para que se incorporen nuevos socios y de esta manera cumplir con el número mínimo exigido por la norma, siempre a los fines de restablecer 
la situación de pluralidad, aunque no suele decir qué efectos jurídicos provocaría el no restablecimiento de aquella pluralidad, dentro del plazo establecido y sin que tampoco declare que ello constituya una causal de disolución; todo lo cual no deja de sugerir importantes reflexiones y hasta posturas interpretativas encontradas sobre el tema, lo que será abordado al momento de reflexionar sobre la consagración de esta figura en el ordenamiento patrio.

\section{Notas respecto de la fundamentación dogmática}

La fundamentación dogmática de las sociedades unipersonales es un tema que demanda para sí una tesis doctoral. Es un estudio apasionante, complicado, que exige mucha profundidad, por cuanto de lo que se trata en esencia es de redimensionar y replantearse toda la teoría tradicional acerca de las sociedades capitalistas, empeño que por razones de pertinencia es imposible acometer en este pequeño espacio investigativo. Sin embargo, es necesario dejar plasmado los ejes en torno a los cuales gira el análisis cuando de fundamentación dogmática de sociedades unipersonales se trata, que en este espacio solo abordamos a manera de presentación toral. Los referidos ejes son: Régimen jurídico, fundación, publicidad, estructura organizativa, órgano de administración, etc.

En virtud de lo anterior, para iniciar a tratar el tema de la sociedad unipersonal, es importante establecer en qué consisten las sociedades unipersonales, puesto que gramaticalmente hablando nos encontramos ante una contradicción de término o bien una antinomia, en vista que en la concepción tradicional sociedad, es el contrato por medio del cual “... los socios se obligan mutuamente a combinar sus recursos o sus esfuerzos para la realización de un fin común, de carácter preponderantemente económico, pero que no constituya una especulación comercial." (Rodríguez, 1977, p. 13).

De lo anterior podemos deducir, que la sociedad - en su visión tradicional- está conformada por una pluralidad de sujetos que se unen para la realización de un fin común, por lo que si tomamos el término sociedad en su literalidad, la sociedad unipersonal es en sí una contradicción en lo que a término respecta, puesto que no se puede pensar en una sociedad con un solo socio, pero dogmáticamente hablando no existe tal contradicción, puesto que las mismas caben perfectamente en las sociedades capitalistas, tal y como se procederá a demostrar a continuación. 
Además de la concepción contractual, la sociedad "determina el nacimiento de una persona jurídica, supone una serie de vínculos jurídicos permanentes, que no se extinguen por el cumplimiento, sino que, por el contrario, este es condición previa para el funcionamiento del contrato como tal..." (Rodríguez, 1977, p. 14), por lo que si tomamos que el nacimiento de la sociedad se da por medio del contrato suscrito entre los socios, para la creación del contrato de sociedad este necesariamente debe existir pluralidad de sujetos (por lo menos dos), por lo que desde aquí quedaría anulada la posibilidad de constituir una sociedad unipersonal, puesto que si él la constitución de una sociedad fuera por medio de un contrato o una relación jurídico - obligatoria se requeriría al menos dos personas, en el entendido que se está realizando a través de un contrato, ya que es impensable jurídicamente hablando de un contrato con una sola parte.

Como podemos observar, tradicionalmente el Derecho de sociedades está encaminado a regular las relaciones de los distintos miembros de una sociedad mercantil y le da a estos una ficción jurídica con la cual les permite actuar con el medio de forma unitaria, como un solo sujeto el cual tiene derechos independientes de los derechos de los socios como personas naturales.

Así mismo, en la tradicional concepción de las sociedades mercantiles lo que prima es el ánimo de colaboración o el "animus societatis" entre los socios y esto tiene como consecuencia que se produzca una unidad en la asociación, unidad la cual permite estar ante un interés diferente al individual de los socios, ya que éste pasa a un segundo plano y pasan a un primer plano los intereses comunes, que a la vez son los intereses de la sociedad misma. Por lo que como ya se dijo los socios se unen y dejan sus intereses personales para unirse a los intereses de la sociedad como tal.

Esto, es logrado en el momento de constitución de la sociedad, que es cuando se pactan las reglas con las cuales se van a regir los socios, para el objeto, manejo y administración de la sociedad, lo cual es plasmado desde el documento de constitución de la sociedad y sus estatutos. "Los socios limitan entonces su libertad individual con reglas de conducta enderezadas a la realización de un fin que, por ser unitario, se persigue con medio unitarios”. (Gabino Pinzon, 1968, P. 23). 
En la doctrina más moderna, se ha gestado una nueva teoría en la que se entiende como sociedad un negocio jurídico y no como un contrato ya que lo que en este caso importa es el fin con el que se está creando la sociedad y no la manera de su creación, “... parte de la doctrina se ha inclinado por la opinión negativa respecto de la naturaleza contractual del llamado contrato de sociedad." (Joaquín Rodríguez Rodríguez, 1977, P. 15.).

En vista de lo anterior, se puede afirmar que "el fin de la asociación trasciende la concreta personalidad de sus miembros, por lo que resulta plenamente independiente de la suerte de quienes la componen efectivamente" (De Eizaguirre, 2001, p. 27), por lo que no es relevante quienes conforman la sociedad ya que esto no es de importancia para la subsistencia y funcionamiento de la sociedad.

Si bien es cierto, la unipersonalidad violenta la característica más conocida y tradicional de las sociedades mercantiles como lo es la pluralidad de miembros; sin embargo, en la práctica las legislaciones en las que no se le ha dado un reconocimiento legislativo a las sociedades unipersonales se requiere una pluralidad de socios para poder realizar la constitución y su posterior inscripción en el Registro Público Mercantil.

Se ha recurrido al uso de testaferros (como una forma de eludir la norma) o bien "hombres de paja", lo que resulta en la realidad en la conformación de una sociedad unipersonal material o bien en la creación de una sociedad con pluralidad de miembros para que una vez inscrita la sociedad y la misma haya iniciado su operación, las acciones o particiones sociales pasen a un solo socio, originándose de esta forma una sociedad unipersonal sobrevenida, situación que la mayoría de las legislaciones tal como es el caso de Francia tolera de manera temporal; sin que esto tenga como consecuencia la disolución automática de la sociedad, con la esperanza que dicha sociedad vuelva en algún momento a tener pluralidad de miembros, y permitiendo a cualquier tercero interesado solicitar judicialmente la disolución de la sociedad, por lo que si ningún tercero solicita la disolución judicial de la sociedad ésta puede permanecer en el tráfico mercantil perennemente.

Algunos juristas, consideran a las sociedades unipersonales como una forma atípica de las sociedades capitalistas, teniendo a ésta como una excepción a la normal pluralidad de las sociedades capitalistas. 
Sin embargo, gracias al esfuerzo de algunos juristas se ha conseguido el cambio de percepción de las sociedades capitalistas, dejando de ser tomadas éstas como un simple medio de unificación de una pluralidad de socios que persiguen un fin común, mediante la unión de sus capitales al realizar una actividad mercantil y ha pasado a fungir como un instrumento de organización de empresa.

Con este cambio de percepción de las sociedades capitalistas, se deja sentada la posibilidad que el esquema de organización de una sociedad pueda ser utilizado tanto por un socio único como por una sociedad con varios, ya que el número de socios de una sociedad capitalista puede fluctuar durante la vida de la sociedad sin que esto llegue a afectar su funcionamiento, debido a que en este tipo de sociedades, lo esencial para su funcionamiento es su patrimonio; puesto que las acciones o particiones sociales pueden ser traspasadas fácilmente de un socio a otro o bien a la misma sociedad, no siendo necesaria una pluralidad de socios, debido a que el capital social puede estar en manos de un solo socio.

Las sociedades de capital son por antonomasia deíndole patrimonialistas, todas sus relaciones comerciales giran en torno al capital social, que es el garante en el cumplimiento de sus obligaciones, las decisiones se adoptan por medio de órganos, despersonalizados de las personas individuales que se encuentran en su base; por lo que no es necesaria una pluralidad de socios para poder llevar a efecto su funcionamiento, esto es debido a que los socios participan en un negocio jurídico-sociedad-con una parte de su patrimonio que se traduce en participaciones sociales o acciones que son las que a la postre integraran el capital social o fondo común, por lo que se despersonifica la condición de miembro o socio ya que dicho carácter se vuelve plenamente fungible, al ser la nueva persona que ha nacido -sociedad- quien participará en el tráfico jurídico como sujeto de derecho nuevo y autónomo.

Cabe recalcar que la sociedad por acciones fue creada con el espíritu que hubiera igualdad entre los socios, pero esto con el tiempo se ha venido desmitificando, propendiéndose a una desigualdad entre el derecho de los socios, a partir del grado de participaciones sociales de cada quien, y justo esta desigualdad -justa y admitida- se funda en redimensionar el rol protagónico que tiene en las sociedades capitalistas el capital social.

Si hemos sostenido a lo largo de este trabajo que lo que destaca en una sociedad capitalista es su capital porque con él responderá de las 
obligaciones contraídas, entonces será intrascendente determinar quién o quiénes aportaron para conformar ese capital social, pues en definitiva lo que importa a los terceros y al tráfico es la debida conformación y solidez de ese capital, bien tenga como antecedentes a accionistas plurales o únicos. Antes de admitirse llanamente esta tesis -unipersonalidad originaria- la "desigualdad en los derechos de los accionistas" permitió situaciones de unipersonalidades materiales, a través de la figura del socio tirano, en virtud de la cual se mantenía una pluralidad formal, aparente, más se concentraba en poder de un solo socio el mayor porcentaje dentro del paquete accionario, lo cual permitía una mayor representación en el ejercicio de los derechos políticos y económicos y con ello el control de facto de la sociedad.

En atención a lo anterior, concuerdo con Carbajo Cascón en que:

La existencia de una sociedad de capital con un solo socio no contradice su subsistencia como persona jurídica, pues esta no es sino un ente ficticio que sirve como instrumento o técnica jurídica de actuación e imputación unitaria de una organización jurídica plenamente independiente del sustrato propio (p. 107).

Así mismo, en la sociedad no existe relación entre los miembros de la sociedad respecto los unos con los otros, sino que la relación existente es entre cada miembro a título personal con la sociedad de la cual forman parte, lo cual desvanece la tradicional tesis de la afectio societatis. De esto se desprende que "La sociedad forma una persona jurídica distinta de los socios individualmente considerados" (Pinzon, 1968, p. 25).

Es por esto que, la razón social designada a la sociedad cobra un gran valor, puesto que la misma cobija los actos, contratos o relaciones sociales y no los actos, contratos o relaciones personales de los socios; así mismo, la razón social es un medio para facilitar a los terceros que contratan o tienen relación con la sociedad el diferenciar entre los actos sociales y los actos de los socios en su carácter personal; además de permitirle el informarse del lugar que tienen los socios en cuanto a las operaciones llevadas a cabo en nombre e interés de la persona jurídica de la cual es socio, ya que "la persona jurídica es la única que responde con su patrimonio de los actos ejecutados en su nombre" (Pinzon, 1968, p. 30).

La persona jurídica formada, pasa a ser sujeto de derechos y obligaciones independiente de sus socios y por lo tanto, ésta responderá por las obligaciones que contraiga con su capital social. Así mismo, al tercero acreedor de la sociedad le resulta indiferente si ésta tiene una pluralidad 
de socio o es un socio único, puesto que no podrá en principio perseguir sus patrimonios personales, debido a que como ya se dijo es la sociedad quien asume las deudas sociales con su patrimonio.

En las sociedades capitalistas lo realmente importante, es la participación de los socios con su patrimonio pasando a un segundo plano su persona, ya que lo que interesa es el capital que el socio inyecta a la sociedad, proyectado en el capital social, así como las relaciones sociales entre el socio y la sociedad conformada.

El socio con respecto ala sociedad tienela obligación deponer adisposición de ésta su aportación social ya sea al momento de la constitución de la sociedad o bien posteriormente, por lo que su persona da igual, ya que sea él $u$ otra persona la que se mantenga en la sociedad, esto no afecta en lo más mínimo su funcionamiento. Por lo que la condición de socio en las sociedades capitalistas está dada por la acción o acciones que posea, pudiendo estas acciones o participaciones sociales estar en varias o una sola mano de manera indiferente para el funcionamiento de la sociedad, ya que las bases de las sociedades capitalistas son esencialmente patrimoniales y no descansan sobre una pluralidad de socios. De esto se desprende que, una persona tendrá la calidad de socio o socios dependiendo de la cantidad de acciones o particiones sociales posea, pudiendo perfectamente llegar a tener en su mano todas y cada una de las acciones o particiones sociales en que se encuentre dividido el capital, configurándose de esta forma una sociedad unipersonal.

Lo anteriormente señalado, puede darse desde la misma constitución de la sociedad, puesto que la sociedad de capital unipersonal, al mismo tiempo que forma un instrumento jurídico para la organización de empresas, también es utilizada como un medio para poder gestionar de manera unitaria los patrimonios. Por lo que desde el punto de vista dogmático, la estructura de la sociedad capitalista consiste en un capital que se divide en acciones o particiones sociales, una sociedad heterorgánica, lo que fundamentalmente importa es justo esa estructura y funcionamiento, a cuyos fines el hecho de que exista pluralidad de socios $a b$ initio, es totalmente irrelevante.

Es por esto que la unipersonalidad se ampara fundamentalmente en la preponderancia del aspecto institucional de la organización -producto de la concesión de personalidad por el ordenamiento- sobre el aspecto 
contractual, imprescindible en el momento constitutivo pero no durante el normal funcionamiento de la sociedad personalizada conforme al estatuto incorporado. (Carbajo Cascón, 2002, p. 108)

A medida que en el mundo se ha gestado un interés por la empresa como tal, se ha sustituido el concepto de la sociedad de un origen contractual y ha pasado a ser una organización de origen institucional; esto es gracias a que la empresa pasó a ser tomada en cuenta como una estructura económica, por lo que se hace necesario el reconocimiento de la misma en el plano jurídico, para que le sea permitido ser sujeto de derechos y obligaciones. En las sociedades capitalistas, los empresarios encuentran el instrumento necesario para poder llevar a cabo sus fines, ya que ésta es el mecanismo perfecto de organización jurídica que la empresa necesita para poder llevar a cabo sus operaciones y también de esta manera poder convertirse en sujeto de derechos. Así mismo, esto ha beneficiado a los pequeños y medianos empresarios que han encontrado en esta forma societaria, un mecanismo para poder realizar una clara separación entre su patrimonio y el patrimonio de la sociedad de la cual es socio.

En consecuencia, la estructura de las sociedades capitalistas, que tienen como fin primordial el ser instrumento jurídico de organización de empresa, no entra en contradicción con el que la misma pueda nacer con un socio único, o bien nacer con pluralidad de socios y con el paso del tiempo las acciones o particiones sociales pasen a una sola mano.

De lo anterior ya no debe verse a la sociedad unipersonal como una situación anormal o atípica por la que puede pasar una sociedad de capital, sino como una situación normal ya sea al momento de su constitución (sociedad unipersonal originaria) o bien posteriormente (sociedad unipersonal sobrevenida); ya que esto no es más que la evolución natural de las sociedades capitalistas, dadas las necesidades sociales y económicas del mundo actual.

Según Carbajo Cascón (2002) el negocio constitutivo de una sociedad de capital anónima o limitada tiene su razón de ser primaria en la creación (conforme al esquema legalmente predeterminado) de una organización objetivada autónoma de carácter patrimonial que, a la postre, procure la satisfacción de una finalidad de naturaleza normalmente lucrativa (lucro objetivo como aprovechamiento de ventajas económicas en general); y todo ello independientemente del número de miembros que concurran a su conformación negocial. 
Ya para ir finalizando esta exposición de la fundamentación dogmática de la sociedad capitalista unipersonal, es necesario fijar un concepto de Sociedad Capitalista Unipersonal, en este sentido Abboud Castillo (2006), a mi criterio ofrece un concepto idóneo, pues según éste:

La sociedad unipersonal es una sociedad de capital, del tipo anónima o de responsabilidad limitada, que supone la concentración de todas las acciones o participaciones sociales en poder de un único socio, que podrá ser una persona física, individual o una persona colectiva (p. 8).

Una vez dejado en claro el concepto de sociedad unipersonal de capital, es importante dar una mirada a una definición normativa, más precisamente la proporcionada en el capitulo XI, de la Ley de Sociedad de Responsabilidad Limitada española, (Rodriguez-Cano, Martinez, \& Vega, 1999, p. 1921). denominada "Sociedad Unipersonal de Responsabilidad Limitada" en su artículo 125 establece que:

se entiende por sociedad unipersonal de responsabilidad limitada:

a) La constituida por un único socio, sea persona natural o jurídica;

b) La constituida por dos o más socios cuando todas las participaciones hayan pasado a ser propiedad de un único socio. Se consideran propiedad del único socio las particiones sociales que pertenezcan a la sociedad unipersonal.

De lo anterior, se desprende que, por sociedad unipersonal se entiende aquella sociedad constituida por un sólo socio pudiendo ser éste una persona natural o jurídica, la que tiene su origen en un negocio jurídico unilateral, en el que detalla la declaración unilateral de una sola persona y en las que debe cumplir con las formalidades previstas por la Ley para su conformación, este tipo de sociedades es también conocida como sociedad unipersonal originaria. Es igualmente sociedad unipersonal, ahora sobrevenida, aquella que ha nacido con una pluralidad de socios y por cualquier causa las acciones o participaciones sociales han pasado a manos de un solo socio.

Para finalizar este apartado, podemos decir que las sociedades capitalistas unipersonales, no debe nacer necesariamente por un contrato, sino que su nacimiento puede darse por la simple declaración de voluntad de una sola persona que declare su propósito de fundar una organización 
societario - capitalista, conforme la legislación de la materia en las legislaciones que tengan normada y permitida la existencia de sociedades capitalistas de un solo socio o sociedades unipersonales - ab initio- y éstas deben considerarse como una forma más de manifestación de las sociedades capitalistas, ya que como se dijo el objeto fundamental de las sociedades capitalistas es el negocio de organización de la empresa, y no el conjunto de personas agrupadas para conformar una sociedad, tal como se creía tradicionalmente, puesto que las sociedades unipersonales no es más que una forma de estar de las sociedades capitalistas y no una forma de ser o situación anómala, por la que éstas puedan pasar.

Así mismo, las sociedades capitalistas unipersonales, como ya se dejó claro no son un tipo distinto o atípico, ni mucho menos un tipo organizacional especial, sino que es una forma coherente con los principios básicos de una sociedad de capital, ya sea una sociedad anónima o una sociedad de responsabilidad limitada, la que desde su nacimiento el dueño o titular de las acciones o particiones sociales en las que está dividido el capital, pertenece a una sola persona, sin alterarse por esto su estructura jurídica o su formación como persona jurídica. Ya que según Carbajo Cascón (2002):

la unipersonalidad no es una forma de ser de la sociedad de capital sino que es más bien una manera de estar una sociedad anónima o limitada en un momento determinado de su existencia, sin perjuicio de que esa situación o manera de estar perdure o sea meramente temporal, dado el carácter esencialmente mutable de esa situación. (p. 211).

\section{Consagración legislativa de las sociedades unipersonales}

Como hemos visto, la sociedad unipersonal no es una situación atípica por la que puede pasar una sociedad, sino que en la doctrina moderna ésta se considera como una forma más de estar de las sociedades capitalistas, es por esto que la tendencia legislativa ha sido dar reconocimiento legislativo a esta figura jurídica dada la importancia que ha cobrado.

\section{Duodécima directiva CEE en materia de sociedades}

En este sentido, el viejo continente a través dela Duodécima directiva CEE en materia de sociedades, relativa a las sociedades de responsabilidad limitada de socio único, del 21 de diciembre de 1989, regula lo atinente 
a la sociedad unipersonal y requiere a los países que forman parte de la entonces Comunidad Europea - hoy en día Unión Europea- adoptar las disposiciones legales, reglamentarias y administrativas para dar cumplimiento a lo dispuesto en la directiva ya relacionada.

Esta Directiva del Consejo fue promulgada con el fin de unificar las legislaciones de la Comunidad Europea en relación con la permisibilidad del régimen de unipersonalidad; ya sea de forma originaria o bien derivada, pues a esa fecha ya varios países de la Comunidad lo tenían regulado en su ordenamiento, cuestión que causó discrepancias entre las legislaciones de los países miembros de la Comunidad. Otra razón de peso que impulsó al legislador comunitario a emitir la Duodécima Directiva es el crear un instrumento jurídico que tolere limitar la responsabilidad de empresario individual.

Cabe señalar que, aunque dicha directiva es aplicable a las sociedades de responsabilidad limitada, deja abierta la posibilidad de aplicar lo establecido en ésta, para efecto de normar las sociedades anónimas unipersonales, en el caso que un Estado decida reconocerlas.

Así mismo, la Duodécima Directiva prevé que en el caso que un Estado miembro contemple en su Derecho interno, que un empresario individual puede constituir empresas de responsabilidad limitada, delimitado parte de su patrimonio, para utilizarlo en su actividad empresarial, dicho Estado podrá no permitir en su ordenamiento interno la constitución de sociedades unipersonales.

Algo importante de hacer notar, es quela Directiva restringe a las personas jurídicas el ser socio único de más de una sociedad unipersonal, además exige la publicación en el caso que las acciones o particiones sociales han sido reunidas en una sola mano, configurándose una sociedad unipersonal sobrevenida. Sin embargo, en este sentido el legislador comunitario no establece quién tiene la responsabilidad o quién está legitimado ante el registro para solicitar la inscripción de la situación de unipersonalidad como tampoco dispone qué tipo de documentación es exigida, es decir, si se requiere documento público o basta con una simple declaración y la exhibición de documentos que acrediten la adquisición de todas las acciones o participaciones de una sociedad. (Carbajo Cascón, 2002). 
Así mismo, exige que los contratos entre el socio y la sociedad unipersonal deben ser realizados por escrito, y el socio único asume la potestad de la Asamblea de Socios y las decisiones tomadas por el socio único deben constar en acta. El legislador con estas medidas lo que pretendió es "garantizar la transparencia en los asuntos sociales y, en consecuencia, de velar por la seguridad de los terceros que entren o puedan entrar en la relación con el ente, así como la seguridad del tráfico en general..." (Carbajo Cascón, 2002).

El legislador comunitario con la Duodécima Directiva, estableció de manera muy escueta la regulación a las sociedades unipersonales que los países miembros debían amoldar en sus respectivas legislaciones con el fin de unificarlas, y lo que no se reguló en materia de sociedad unipersonal se sobreentiende deberán obedecer el régimen general para las sociedades de responsabilidad limitada y anónima de conformidad con la legislación interna de cada país.

Es necesario destacar que a pesar de la Duodécima Directiva y sin desconocer su mérito, existen países, como Portugal, que han optado por la figura de la Empresa Individual de Responsabilidad Limitada (EIRL), aún y cuando reconocen las sociedades unipersonales, son más proclives a optar o establecer EIRL.

\section{España}

Veamos como se ha desarrollado el reconocimiento de la unipersonalidad en el contexto español.

Carbajo Cascón (2002) señala que la primera vez, que el Derecho español hizo referencia a la sociedad de capital unipersonal, fue con la Resolución de la Dirección General de los Registros y del notariado del 11 de abril de 1945, a establecer que las acciones de una sociedad concurran en una solo mano de manera permanente o temporal no es causal de disolución de la misma.

En España la Ley de 17 de julio de 1951 de Régimen Jurídico de Sociedades Anónimas, a la luz de lo recopilado por Rodriguez-Cano, Martinez, \& Vega (1999) mantiene lo establecido en la Resolución de la Dirección General de los Registros y del Notariado, puesto que el legislador consideró que la reunión de todas las acciones en la mano de 
un solo socio (sociedad unipersonal sobrevenida) no era causal suficiente para declarar la disolución de la sociedad, pues con esto el legislador quiso legalizar de alguna manera las sociedades anónimas formal o materialmente unipersonal; así mismo por primera vez en el derecho Español se regula la constitución de una sociedad anónima unipersonal únicamente para los entes públicos estatal, provincial o municipal.

En virtud de la Duodécima Directiva CEE en materia de sociedades, relativa a las sociedades de responsabilidad limitada de socio único, del 21 de diciembre de 1989, el panorama español cambió en lo referente al Derecho societario, en particular en lo relativo a sociedades de capital, pues con la promulgación del Real Decreto Legislativo 1564/1989, de 22 de Diciembre, que aprueba el texto refundido de la Ley de Sociedades Anónimas y su reforma, según Rodriguez-Cano, Martinez, \& Vega (1999), por virtud de la disposición adicional segunda 23, se introduce un nuevo artículo, el 311, en la Ley de Sociedades Anónimas el que reconoce que "será de aplicación a la sociedad unipersonal lo dispuesto en el capitulo XI de la Ley de Sociedades Anónimas de Responsabilidad Limitada”. (Rodriguez-Cano, Martinez, \& Vega, 1999, p. 813).

Posteriormente, la Ley de Sociedades de Responsabilidad Limitada, Ley 2/1995, de 23 de marzo, Rodriguez-Cano, Martinez, \& Vega, (1999) establece el régimen jurídico aplicable a la constitución y funcionamiento de las sociedades de responsabilidad limitadas unipersonales, ya sea por haber nacido con un solo socio o bien por concentrarse en una sola mano las acciones; así mismo, estableció que si dentro de los 6 meses en que deviniere la unipersonalidad sobrevenida el socio único responderá de manera solidaria e ilimitada por las deudas sociales contraídas, pero una vez efectuada la inscripción el socio no responde por las deudas sociales.

Con esta Ley, el legislador no admite en su ordenamiento jurídico únicamente a las sociedades de responsabilidad limitada unipersonales; sino que además incluye a las sociedades anónimas unipersonales.

Y con esto la empresa individual se puede beneficiar del tipo societario que más le convenga para delimitar su responsabilidad en el quehacer empresarial, siempre y cuando se cumplan con los requisitos establecidos por sus respectivas leyes. 
Por consiguiente, de conformidad con ambas legislaciones (Ley de Sociedad Anónima y Ley de Responsabilidad Limitada) las sociedades unipersonales podrán ser constituidas en sociedades anónimas o en sociedades de responsabilidad limitada y seguir subsistiendo las que adquieran tal condición, por la concentración de todas las acciones o particiones sociales en una sola mano. En el caso de las sociedades anónimas unipersonales, éstas en lo relacionado a su unipersonalidad se estarán en lo dispuesto en la Ley de Sociedad de Responsabilidad Limitada que de conformidad con el art. 311 ha sido incorporado a dicha ley, y el régimen general de las sociedades anónimas deberá ajustarse a lo normado en la Ley de Sociedades Anónimas.

Siendo que tanto para las sociedades anónimas y de responsabilidad limitada su regulación es la misma (Ley de Sociedad de Responsabilidad Limitada), procederé a realizar un breve recorrido por la misma a fin de conocer lo normado en la legislación Española en lo relativo a sociedades unipersonales.

El Capítulo XI denominado Sociedad Unipersonal de Responsabilidad Limitada, en su art. 125, Rodriguez-Cano, Martinez, \& Vega (1999), contempla las dos formas ya reconocidas en la doctrina de sociedad unipersonal, como lo son la sociedad unipersonal originaria, a la que se refiere el literal a) del artículo precitado; y la sobrevenida, recogida en el literal b).

En el caso del literal a) del art. 125, la novedad es que ya no se requiere la pluralidad de socios para la constitución, sino que la misma puede nacer por la voluntad de una sola persona.

En cuanto al literal b) del articulo ya relacionado, permite la reunión de las particiones sociales en una sola mano sin que esto signifique la disolución de la sociedad, conservando el único socio su patrimonio separado del societario (siempre y cuando se haya realizado la debida inscripción ya relacionada).

En este mismo sentido, Rodriguez-Cano, Martinez, \& Vega (1999), el art. 126 establece la obligatoriedad de hacer constar en escritura pública la declaración de haber constituido una sociedad de responsabilidad limitada, o bien que un solo socio ha pasado a ser propietario de todas las particiones, dicha escritura pública debe ser inscrita en el Registro 
Mercantil, quien a su vez en la inscripción se hará saber el nombre del socio único. En este caso, el legislador español ha superado las exigencias de la Duodécima Directiva, pues ha ampliado "las exigencias de comunitarias al obligar también la inscripción registral de los cambios de socio único, así como la perdida de situación de unipersonalidad." (Carbajo Cascón, 2002, p. 398).

También, la sociedad unipersonal deberá expresar en toda papelería, correspondencia etc., su condición de unipersonalidad, requisito que considero es más que suficiente para que los terceros conozcan de la unipersonalidad de la sociedad; pues si se le solicitara el indicar en su denominación social la situación de unipersonalidad ésta debería cambiar cada vez que una sociedad pase de ser unipersonal o tener pluralidad de socios.

Así mismo, a mi parecer esta disposición es con el fin de mantener la seguridad jurídica, y la seguridad del tercero que realiza transacciones comerciales con la sociedad y que éste sepa de manera concreta con quien está contratando y así mismo la cautela en estos casos toma sentido por haber la posibilidad que el socio único tome decisiones en contra de la buena andanza de la sociedad o bien exista un infracapital social. Por lo que, en el caso de las sociedades de capital unipersonal debe tener un régimen jurídico más riguroso. Esta obligatoriedad de inscripción el Registro Mercantil para dar publicidad a la situación de unipersonalidad encuentra su asidero en la Duodécima directiva precitada.

Rodriguez-Cano, Martinez, \& Vega (1999), en relación con las decisiones del socio único el art. 127 establece que el socio único ejercerá las competencias de la Junta General; así mismo norma que las decisiones tomada por éste deben realizarse por escrito en acta la cual debe firmar el socio o a quien haya facultado para este fin, pudiendo ser ejecutadas por el socio único o bien por los administradores de la sociedad.

Esta normativa, al igual que el artículo anterior, encuentra su asidero en la Duodécima directiva en la que se establece lo relacionado a las decisiones tomadas por el socio único.

Con lo normado en el art. 127, lo que se pretende es dejar consignada la sociedad unipersonal sea esta anónima o de responsabilidad limitada y conservar su estructura organizativa. Ya que se deja la posibilidad de 
nombrar un administrador o administradores, utilizando para ello las reglas y los mecanismos generales aplicables a toda sociedad.

Así mismo, en el caso del acta que queda consignada en el libro, ésta a su vez debe cumplir con los requisitos que se pide en el régimen general de las sociedades para poder proceder a su publicación en el Registro Mercantil.

Para Rodriguez-Cano, Martinez, \& Vega (1999) el art. 128 norma lo relacionado a la contratación del socio único con la sociedad unipersonal, y se indica que éstos obligatoriamente deben constar por escrito o en la forma documental que exija la Ley; dicho contrato debe ser transcrito en el libro registro de la sociedad y el que debe ser legalizado de conformidad con lo dispuesto para los libros de actas de las sociedades.

Así mismo, prevé que en caso de insolvencia provisional o definitiva del socio único o de la sociedad, no serán oponibles a la masa aquellos contratos comprendidos en el apartado anterior que no hayan sido transcritos al libro registro y no se hallen referenciados en la memoria anual o lo hayan sido en memoria no depositada con arreglo a la Ley.

El art. 128, va más allá al establecer que desde la fecha de la celebración de los contratos, el socio único va a responder frente a la sociedad de las ventajas directas o indirectas que haya obtenido en perjuicio de la sociedad como consecuencia de dichos contratos.

En este caso, el socio al contratar con su sociedad está ante los mismos intereses y en este caso quien puede verse perjudicados son los terceros que contraten con la sociedad.

La posibilidad de que el socio único celebre contratos con la sociedad es, sin duda, el aspecto más delicado del régimen general de la unipersonalidad; pues, la contratación entre el socio único y la sociedad puede llegar a ser una forma disfrazada de descapitalizar la sociedad, lo que resulta en perjuicio del tercero que contrata con la sociedad al momento de ir en contra de ésta. La sociedad puede presentar estado de insolvencia, cuestión que considero el legislador trató de evitar al establecer la responsabilidad del socio de las ganancias que éste haya obtenido en detrimento de la sociedad. 
Según Rodriguez-Cano, Martinez, \& Vega (1999) el art. 129 establece que pasados seis meses desde que la sociedad adquirió el carácter de unipersonal, sin que esta condición se hubiera inscrito en el Registro Mercantil, el socio único responderá personal, ilimitada y solidariamente de las deudas sociales contraídas durante el periodo de unipersonalidad. Una vez inscrita tal situación de unipersonalidad el socio único no responderá por las deudas sociales realizadas con posterioridad a la inscripción. Este artículo fue retomado de la Duodécima Directiva.

\section{Mirada a la realidad latinoaméricana en materia de unipersonalidad}

Latinoamérica se ha quedado atrás, en cuanto a la tendencia legislativa Europea, quienes en sus ordenamientos jurídicos, como ya se vio, han admitido la constitución de una sociedad de capital unipersonal, ya sea de forma originaria o bien sobrevenida.

En este sentido, las legislaciones de la mayoría de naciones latinoamericanas se encuentran en un gran desfase en cuanto a este tema, pues, a esta altura nos encontramos con situaciones de unipersonalidad originaria material que no son reconocidas de manera expresa por los ordenamientos jurídicos. Sin embargo, dentro de los países del área, Colombia ha sido uno de los pocos que tienen reguladas las empresas unipersonales, que es un paso más en la evolución hacia el reconocimiento legislativo de la sociedad de capital unipersonal, por lo que considero de importancia darle una mirada a su legislación.

\subsection{Colombia}

Colombia con la Ley, $\mathrm{N}^{\circ} 222$ del 21 de diciembre de 1995, vigente a partir del 21 de junio de 1996,( recuperado el 24 de abril de dos mil diez,http:// www.cntv.org.co/cntv_bop/basedoc/ley/1995/ley_0222_1995.html) admite la empresa unipersonal por medio de reforma al Código de Comercio de ese país, en materia societaria. Lo relativo a la Empresa Unipersonal, es normado de manera muy escueta pues el legislador únicamente utiliza diez artículos de la referida Ley, para tratar la unipersonalidad.

Dicha Ley, establece que mediante la empresa unipersonal un empresario o una persona jurídica puede destinar parte de su capital para la realización de una o varias actividades de carácter mercantil. 
La empresa unipersonal una vez inscrita pasa a formar una persona jurídica, distinta de su propietario.

En su art. 72 establece que la constitución de la empresa unipersonal debe realizarse por escrito, y dentro de los requisitos que debe contener la constitución cabe destacar el que se le exige al empresario que haga una enunciación clara y completa de las actividades principales; a menos que se exprese que la empresa podrá realizar cualquier acto lícito de comercio y el monto del capital haciendo una descripción pormenorizado los bienes aportados, con estimación de su valor, y este responderá por el valor asignado a los bienes en el documento constitutivo.

Se le prohíbe al empresario el retirar cualquier clase de bienes de la empresa unipersonal por él conformada, a menos que sean utilidades a las cuales tenga derecho.

La legislación Colombiana, no tolera que el empresario contrate con la empresa unipersonal, ni permite que empresas unipersonales constituidas por el mismo titular contraten entre sí. La legislación colombiana castiga al empresario que incumple esta norma con la ineficacia de tales actos de pleno derecho.

Al ser una empresa unipersonal y no una entidad societaria, la legislación prevé que al pasar la empresa a manos de dos o más personas, se otorgan seis meses para que los socios elijan el tipo societario al cual se acogerán y realicen los estatutos correspondientes, esto deberá realizarse a través de escritura pública que debe ser suscrita por todos los socios para su posterior inscripción el Registro Mercantil. En este caso, la nueva sociedad pasará a asumir sin solución de continuidad los derechos y obligaciones de la empresa unipersonal.

Así mismo, en el caso que una sociedad se disuelva por haberse reducido el número de socios, ésta podrá pasar a ser una empresa unipersonal, siemprey cuando tal situación se formalice por documento público, el cual debe ser posteriormente inscrito en el Registro Mercantil. Esta facultad otorgada al socio unipersonal debe ser formalizada dentro de los seis meses posteriores al haber ocurrido la situación de unipersonalidad. Al igual que el caso anterior, la empresa unipersonal asumirá, sin solución de continuidad, los derechos y obligaciones de la sociedad disuelta. 
La legislación indica las causas por las cuales una empresa unipersonal puede ser disuelta, las que procederé a enunciar:

1. Por voluntad del titular de la empresa,

2. Por vencimiento del término previsto, si lo hubiere, a menos que fuere prorrogado mediante documento inscrito en el registro mercantil antes de su expiración.

3. Por muerte del constituyente cuando así se haya estipulado expresamente en el acto de constitución de la empresa unipersonal o en sus reformas.

4. Por imposibilidad de desarrollar las actividades previstas.

5. Por orden de autoridad competente.

6. Por pérdidas que reduzcan el patrimonio de la empresa en más del cincuenta por ciento.

7. Por la iniciación del trámite de liquidación obligatoria.

Sin embargo, la disolución de la sociedad puede evitarse con la adopción de medidas legales, dependiendo de la causal por la cual se disolverá la empresa.

La legislación colombiana prevé que lo no normado en relación con la empresa unipersonal, se deberá atender lo relativo a las sociedades comerciales y en especial lo relativo a las leyes de responsabilidad limitada.

\section{Valoración de la admisibilidad de las sociedades unipersonales en el ordenamiento jurídico nicaragüense}

Como hemos visto, en la legislación de otras naciones y en el caso específico de la Unión Europea, éstos han incorporado a sus legislaciones la posibilidad de constituir una sociedad capitalista unipersonal, también como observamos en el área latinoamericana, en el caso específico de Colombia, su legislación con la Ley No. 222 del 21 de diciembre de 1995, se ha dado el primer paso para separar la responsabilidad patrimonial del empresario, a través de la empresa unipersonal.

Como es bien sabido, el pequeño y mediano empresario practica su actividad económica poniendo como respaldo para responder de las relaciones contractuales que se deriven de sus actuaciones mercantiles su patrimonio total, asumiendo el riesgo pleno en sus relaciones 
comerciales; pues jurídicamente hablando, éste es el que debe cargar con la responsabilidad de sus actuaciones. Por lo que, su responsabilidad empresarial necesariamente se traduce en un posible detrimento de su patrimonio, dado que mientras más grande es el riesgo empresarial que toma, mayor será el daño patrimonial que éste reciba, pudiendo traer como consecuencia su desaparición en el mundo empresarial. Ya que éste responde por la totalidad de sus bienes, al no existir una separación patrimonial entre los bienes que se utilizan para la actividad empresarial y el patrimonio personal del empresario.

Precisamente, aquí radica la importancia de tener regulado en nuestra legislación la posibilidad de constituir una sociedad capitalista unipersonal; pues con ésta se da la oportunidad al empresario individual de acogerse a una de estas formas societarias para de esta forma delimitar la responsabilidad que sobrevengan de la explotación de la sociedad, la que estará limitada al patrimonio por éste aportado y no podrán las deudas sociales de ninguna manera traspasar al patrimonio personal a menos que la ley le impute la responsabilidad personal a éste por sus actuaciones en nombre de la sociedad.

Lo anteriormente relacionado, nos sirve como antecedente para proceder a analizar si en nuestra legislación tiene cabida la posibilidad de normar el régimen de sociedades capitalistas unipersonales, ya sean originarias o bien sobrevenidas, para dar protección al pequeño y mediano empresario; pues tendría un instrumento que le permita delimitar su responsabilidad al realizar cualquier actividad comercial o mercantil, ya que su responsabilidad estará limitada al capital social aportado.

También, al incorporar en nuestro ordenamiento jurídico la sociedad capitalista unipersonal, los empresarios no tendrían la necesidad de utilizar a los llamados hombres de paja o testaferros con el fin de evadir la norma para llevar a efecto la constitución de la sociedad con pluralidad de socios; por lo que con la incorporación legal de la sociedad unipersonal estaríamos ante un sinceramiento del sistema jurídico, pues se legalizaría un secreto a voces.

Para iniciar el análisis, debemos detenernos a estudiar el sistema de sociedades capitalistas permitido en nuestra legislación, por lo que si nos remitimos al art.118 de nuestro Código de Comercio vigente nos 
encontramos que este únicamente reconoce cinco formas o especies de sociedades mercantiles, que son la sociedad en nombre colectivo, sociedad en comandita simple, sociedad anónima, sociedad en comandita por acciones, sociedad cooperativa, última ésta que emigró a una Ley especial.

Dentro de esta lista taxativa, dada por la Ley nos encontramos que las sociedades capitalistas reconocidas son la sociedad en comandita por acciones y la sociedad anónima. Siendo que las sociedades comanditas por acciones no calzan dentro de los rasgos necesarios para poder éstas en algún momento ya sea al constituirla o posteriormente ser unipersonales, pues requiere "de dos clases de socios los comanditarios y los colectivos- como presupuesto de su estructura y funcionamiento para la configuración de los rasgos del tipo, lo cual impide que puedan existir situaciones de socio único sin desnaturalizar su tipología y hacerla inoperante”. (Abboud Castillo, 2006).

Así mismo, de la simple lectura del artículo 118 precitado, se desprende que en él no encuentra cabida la sociedad de responsabilidad limitada, a pesar de la doctrina querer sostener que nuestra legislación mercantil lo permite al establecer en el artículo 137 que “...pueden por pacto los socios limitar su responsabilidad, con tal que se agregue a la razón social la palabra: limitada. (Solórzano Reñazco, 1999, p. 129), ya que considero que con esto se desvirtúa la esencia de la sociedad colectiva como lo es la responsabilidad ilimitada.

Es por esto que, la sociedad de responsabilidad limitada hoy por hoy en nuestro ordenamiento jurídico al ser este un "tipo societario, híbrido entre la sociedad personal y capitalista, acogido por un número importante de ordenamientos jurídicos, no encuentra asidero legal en el Código de Comercio nicaragüense." (Abboud Castillo, 2006).

Dado lo anterior, se hace necesario apartar de nuestro estudio dicho tipo societario - SRL-, pues el mismo no se ajusta a lo normado en otras legislaciones, en las que están claramente reguladas las sociedades de responsabilidad limitada, de base netamente capitalista y no un híbrido entre sociedad personalista y capitalista, y menos como una sociedad meramente personalista como es el caso de lo que se dice regulado en nuestro Código de Comercio. 
1. Posibilidad de unipersonalidad en las sociedades anónimas de conformidad con la legislación nicaragüense

Para iniciar, es importante reafirmar la forma de las sociedades capitalistas, en este caso de las sociedades anónimas de llegar a un estado de unipersonalidad, pues ésta puede ser en la constitución de la misma -unipersonalidad originaria- o bien por pasar a manos de un solo socio las acciones de una sociedad que fue constituida en pluralidad de socios -sociedad unipersonal sobrevenida-. Pues, lo que en este caso interesa es quien es el titular de las acciones sociales en las que está dividida la sociedad, y no el número de socios de la misma.

Tal y como se expresó en el apartado anterior la sociedad de responsabilidad limitada, que es la otra forma societaria que acoge la sociedad unipersonal, no será estudiada, pues en nuestro ordenamiento la misma no se encuentra debidamente regulada, como ha quedado dicho.

En base a lo anteriormente planteado, estudiaremos únicamente a las sociedades anónimas, pues es el único tipo societario capitalista permitido en nuestra legislación que por su estructura y funcionamiento permite la constitución de la misma en unipersonalidad o bien llegar posteriormente a esta forma de estar de las sociedades capitalistas -sobrevenida-.

Dicho esto, puedo afirmar que en nuestro ordenamiento jurídico no se admiten las sociedades unipersonales originarias, pues de conformidad con nuestra legislación mercantil, más precisamente el art. 202 del Código de Comercio nicaragüense, se permite la constitución de una sociedad anónima con un mínimo de dos personas, siempre y cuando cumplan con todos los requisitos necesarios para su validez establecidos en nuestro Código de Comercio. Sin embargo, a pesar que permite la constitución de la sociedad hasta con un mínimo de dos personas, "para su continuación y después de seis meses requiere un numero de accionistas que no sea inferior a tres, pudiéndose pedir la disolución art. 270 C.C..." (Solórzano Reñazco, 1999).

Es de más conocido que en nuestro contexto nacional existen sociedades unipersonales materiales, pues al exigir la legislación vigentela pluralidad de socios para su constitución, el empresario que busca delimitar su 
responsabilidad empresarial, toma mano de socios que hacen las veces de testaferros u hombre de paja, pues con la revisión de la constitución de alguna sociedad nos encontraremos que del cien por ciento de las acciones, existe un socio ampliamente mayoritario, pues a los socios de "favor" únicamente se le asigna acciones simbólicas -en muchos casos únicamente una- para dar la apariencia de pluralidad cuando en verdad estamos ante una sociedad materialmente unipersonal, pues quien controla el destino de la misma es el socio mayoritario, quien es el que tiene realmente el interés de pertenecer a la sociedad.

Nuestro Código deComercio, el cual es deinspiración francesa, la sociedad es vista desde el punto de vista contractual, pues nos damos cuenta de esto con sólo la lectura del artículo 121 del Código de Comercio, el que establece que "Todo contrato de sociedad...” (Solórzano Reñazco, 1999), pues como se observa el Código está pensado para que la conformación de las sociedades mercantiles se den con pluralidad de sujetos.

Sin embargo, en el contexto actual, como ya se dijo la pluralidad es únicamente necesaria para la constitución de la sociedad, más no para su subsistencia en el tráfico jurídico, pues las mismas pueden subsistir en modalidad de unipersonalidad -sobrevenida- hasta seis meses y la ley no es clara al establecer que sucede si la misma no recupera la pluralidad de socios, pues deja al arbitrio de los socios el solicitar la disolución de éste, pudiendo dicha sociedad operar en el tráfico jurídico, por el tiempo que se le ha otorgado para su funcionamiento.

2. Posibilidad de una reforma legislativa a fin de reconocer las sociedades anónimas unipersonales

Tal y como ya ha quedado demostrado, nuestra legislación se encuentra desfasada en el ámbito mercantil internacional, pues a la fecha es impensable para un empresario individual, la posibilidad de delimitar su responsabilidad empresarial al capital utilizado en el tráfico mercantil y que esta responsabilidad no dañe su patrimonio personal; situación que muchos ordenamientos en el mundo han superado desde hace décadas.

Para un posible reconocimiento de la unipersonalidad en las sociedades anónimas se requiere una revisión completa del actual Derecho societario nicaragüense, ya que dentro de sus limitaciones, está lo relacionado al monto mínimo para la constitución de una sociedad; pues en la 
legislación mercantil actual no se encuentra normado, más que lo que establece el art. 206 del CC, que no exige capital mínimo, más la praxis del Registro de la Propiedad Inmueble y Mercantil, no acepta inscribir sociedades cuyo capital sea inferior a diez mil córdobas, cuyo asidero legal se desconoce, más es práctica consolidada.

Siguiendo la línea anterior, en cuanto al desembolso efectivo del capital social al momento de la constitución de la sociedad, pues de conformidad con la legislación vigente, el art. 206 del Código de Comercio indica que "ninguna compañía anónima podrá comenzar sus operaciones mientras no tuviere suscrita siquiera la mitad del capital social, y en dinero efectivo, el $10 \%$ del capital que consista en numerario" (Solórzano Reñazco, 1999, p. 174)., dejando de esta manera en indefensión a los terceros que contratan con la sociedad; pues se puede crear un infracapital, lo que trae aparejado como consecuencia que al momento de los acreedores exigir lo adeudado el capital puede ser insuficiente para cumplir con sus obligaciones, defraudando de esta manera a los terceros que contrataron con la sociedad de buena fe, violentando la seguridad jurídica.

Siendo lo anterior, al momento de realizarse la revisión legislativa a fin de permitir la sociedad anónima unipersonal, se deben tener en cuenta las formalidades necesarias para la constitución de una sociedad capitalistas ya sea esta unipersonal o con pluralidad de socios; pues la unipersonalidad debe ser vista como una forma de estar de las sociedades capitalistas y no como una nueva forma societaria, de forma tal que la realidad del capital social debe ser exigida por la legislación y al menos exigir que todo el capital esté suscrito.

Dentro de la formalidad necesaria para la constitución de toda sociedad capitalista tenemos la exigencia de escritura pública, la que debe ser debidamente inscrita en el Registro Público de la Propiedad Inmueble y Mercantil, a fin de darle la debida publicidad y personalidad jurídica a la sociedad que está iniciando en el tráfico jurídico (art. 19 inciso 2., y 119 $\mathrm{CC}$ ); así mismo, considero que tal y como se encuentra normado en el Derecho español, se deberá dejarindicadola situación de unipersonalidad de la sociedad, con el fin de la seguridad del tráfico jurídico y que los terceros que contratan con la sociedad, conozcan exactamente con quien están contratando. 
Sin embargo, hay que hacer notar que el fraude al que se enfrentan quienes contratan con una sociedad, se puede dar tanto en una sociedad con pluralidad de socios, como en una sociedad unipersonal. Según Chavez Arguello:

en ambos casos pueden presentarse supuestos en los cuales se opta a adquirir personalidad jurídica de una sociedad para encubrir actuares ilícitos que pueden llevar a defraudar al público. (p. 32).

Por esto, ante una posible reforma, se debe establecer en la legislación normas que garanticen la debida regulación del capital de las sociedades, normas debidas de publicidad y control financiero, a fin de garantizar el tráfico mercantil entre las sociedades y los terceros que contratan con ésta.

\section{Conclusiones}

1. Las sociedades mercantiles a través de la historia han sufrido una constante evolución, que ha sido provocada en su mayoría por las situaciones políticas y económicas atravesadas en cada época y de esta forma se sentaron las bases de los tipos societarios mercantiles tal y como los conocemos hoy en día.

2. Dada la evolución de las sociedades capitalistas y la necesidad de delimitar la responsabilidad de los pequeños y medianos empresarios, es que se dio el reconocimiento a las sociedades capitalistas unipersonales, primero en el ámbito doctrinal, para finalmente lograr el reconocimiento legislativo en la Unión Europea.

3. Se debe cambiar la concepción que la sociedad de capital tanto anónima como de responsabilidad limitada, es un contrato, sino mas bien la misma debe verse como un negocio jurídico, el cual puede ser bilateral o unilateral; por lo cual, es indiferente el número de socios que estén detrás, pues una de las principales características de este tipo societario es su inminente carácter patrimonialista.

4. A la fecha las sociedades capitalistas unipersonales como tal, no pueden considerarse una forma anómala o atípica de sociedad de capital; sino mas bien, deben ser consideradas como una forma más de estar de las mismas, forma que se puede dar $a b$ origine o nacer con pluralidad de socios; o de otra forma, las acciones o particiones sociales pasar, sobrevenido, a un único socio. 
5. La unipersonalidad no debe interpretarse como una trasgresión a la estructura y funcionamiento de las sociedades capitalistas, puesto que únicamente se dejan de aplicar a éstas lo relativo a la normativa que suponga pluralidad de socios - como es el caso de votos plurales, derechos preferentes y acuerdos de minorías- manteniendo la misma estructura y funcionamiento.

6. La Comunidad Europea a través de la Duodécima Directiva de la Unión Europea, del año 1989, da el primer paso para unificar la legislación de la región, a fin de permitir la sociedad unipersonal tanto en las sociedades de responsabilidad limitada como anónima, con esto se logró beneficiar a los pequeños y medianos comerciantes o empresarios, que requerían de una forma societaria que les permitiera constituirse de manera individual y al mismo tiempo limitar su responsabilidad.

7. La mayoría de la legislación latinoamericana se encuentra desfasada en comparación con economías más desarrolladas, como es el caso de Europa, que tienen normada la posibilidad de constituir una sociedad ya sea anónima o de responsabilidad limitada unipersonal, puesto que en nuestras legislaciones esto no está contemplado de manera expresa, ya que muchas veces únicamente existe la toleración a la unipersonalidad sobrevenida con la esperanza que en algún momento recupere su estado plural.

8. El ordenamiento nicaragüense no admite la constitución de sociedades anónimas unipersonales originales; sin embargo, tolera las sociedades anónimas unipersonales sobrevenidas, con la esperanza que dicha sociedad en algún momento retome la pluralidad de socios, o bien que la misma deje de existir, todo de conformidad con lo establecido en el artículo 270 CC.

9. Al no permitirse la constitución de sociedades anónimas unipersonales originarias, en el contexto nacional, ha hecho que en la práctica con el fin de evadir la norma, se haga uso de testaferros o bien hombres de paja, con el fin de poder constituir la sociedad en una simulación de pluralidad, cuando en realidad lo que se persigue es la creación de una sociedad de favor o bien en algún momento la trasmisión a una sola mano de las acciones.

10. Urge una revisión del Derecho societario nicaragüense a fin de abandonar la actual concepción contractualista, por una concepción más moderna y acorde con el mundo globalizado, en que hoy en día 
se realizan los actos de comercio, como lo es la concepción moderna que una sociedad no se trata de un contrato, sino más bien de un negocio jurídico.

\section{Recomendaciones}

1. Se hace preciso el promover una reforma al Código de Comercio nicaragüense vigente, con el fin de modernizar el mismo, puesto que muchos de los conceptos en este normados a la fecha se encuentran desfasados, como es el definir a la sociedad como contrato en lugar de negocio jurídico.

2. Dentro de las reformas al Código de Comercio debe incluirse la reforma al art. 202, para permitir la conformación de una sociedad anónima de un solo socio, tanto de manera originaria como sobrevenida, para que los empresarios o comerciantes individuales puedan beneficiarse de este tipo societario a fin de limitar la responsabilidad de sus actuaciones en el tráfico mercantil.

3. Así mismo, la reforma debe apuntar a ampliar los tipos societarios permitidos en el Derecho nicaragüense, a fin que se incluya la sociedad de responsabilidad limitada, que es el otro tipo societario de base capitalista al igual que la sociedad anónima, que es la base perfecta para la unipersonalidad, todo lo cual exigirá reformar el artículo $118 \mathrm{CC}$.

4. También, debe incluirse un articulado a fin de normar el monto mínimo del capital que debe tener una sociedad para poder ser constituida, y un mecanismo para garantizar que dicho capital sea realmente suscrito, y en caso de no serlo las sanciones legales pertinentes, lo cual exigirá reformar el artículo 206 del CC.

5. $\mathrm{Al}$ momento de reconocer las sociedades unipersonales originarias y sobrevenida de forma abierta, deberá incluirse un adecuado sistema de publicidad para estas situaciones de unipersonalidad en el Registro de la Propiedad Inmueble y Mercantil, así como debidas normas de publicidad para los balances financieros y la veracidad del capital social, con el que cuenta una sociedad y cualquier otra circunstancia que garantice la seguridad jurídica. 


\section{Lista de referencias}

\section{Textos}

Abboud Castillo, N. (2006). Fundamentación dogmática de la sociedad unipersonal. Reflexiones en torno a su tratamiento en el ordenamiento jurídico nicaraguese. Tesis de Maestría no publicada, Universidad Centroamericana. Nicaragua.

Carbajo Cascón, F. (2002). La Sociedad de Capital Unipersonal. Navarra: Aranzadi.

Chávez Argüello, A. J. (2008). La Sociedad Unipersonal, su Admisibilidad en el ordenamiento Juridico Nicaraguense. Tesis de Especialización no publicada, Universidad Centroamericana. Nicaragua.

Jiménez Sánchez, G. (2000). Legislacion Mecantil. Barcelona: Ariel.

Pinzón, G. (1968). Sociedades Comerciales. Teoría General (Vol. 1). Bogotá: Temis.

Rodríguez, J. R. (1977). Tratado de Sociedades Mercantiles (T. 1) (5ta. ed.). México: Porrúa.

Rodríguez-Cano, A. B., Martínez, J. D., \& Vega, J. B. (1999). Código de Sociedades Anónimas y de Sociedades de Responsabilidad Limitada. Pamplona: Aranzadi.

Solórzano Reñazco, A. (1999). Glosas al Código de Comercio de Nicaragua (3ra. ed.). Managua: Hispamer.

Uría, R., Menéndez, A., \& García de Enterría, J. (1999). La sociedad anónima: principios fundamentales. En Uría R., Menéndez, A., Alonso Soto, R., Iglesias Prada J. L., Arroyo, I., Paz-Ares, C., et. al. Curso de Derecho Mercantil (pp. 765-781). Madrid: Civitas.

Vicent Chuliá, F. (2004). Introducción al Derecho Mercantil (17ma. ed.). Valencia: Tirant lo Blanch. 


\section{Consultas en línea}

Duodécima directiva CEE en materia de sociedades, relativa a las sociedades de responsabilidad limitada de socio único, del 21 de diciembre de 1989, regula lo atinente a la sociedad unipersonal, Diario Oficial de las Comunidades Europeas No. L 395/40 del 30.12.89. Recuperado el veintinueve de abril de dos mil diez, http:// www.boe.es/doue/1989/395/Loo040-00042.pdf

Ley, No $^{0} 22$ del 21 de diciembre de 1995, Colombia, vigente a partir del 21 de junio de 1996. Recuperado el 24 de abril de dos mil diez, http:// www.cntv.org.co/cntv_bop/basedoc/ley/1995/ley_0222_1995. html) 